\title{
Reclaiming Religion, Religious Studies and the Humanities in the Academy and in National Development
}

\author{
Mary Nyangweso \\ wangilam@ecu.edu
}

\begin{abstract}
Although religion continues to play a significant role in human history and general behavior, it is often minimized, overlooked and discounted especially in the academia and in national development. As a field of study, religious studies encounters numerous challenges, including that of relevance. Claims that religion and its study are irrelevant and impractical in modern society just because of misperceived notions that it is unscientific and therefore unlikely to lead directly to a specialized profession as in the case of the Science, Technology Engineering, and Math (STEM) based fields of study, undermine the significant role of religious studies in the academy and in development. This attitude toward religion and religious studies is expressed broadly regarding the humanities as well. Studies indicate that assertions that students who major in religious studies or the humanities waste time since humanities' graduates are unemployable are not verifiable. This study draws from findings of a national survey and existing secondary data to highlight the place of religion, religious studies and the humanities in the academia and in national development. The study employs intersectionality as a framework to argue for the central role of religion and the humanities in national development.
\end{abstract}

Keywords: Religion, Religious Studies, Humanities, Academic, National Development

\section{INTRODUCTION}

"If I went back to college today, I think I would probably major in comparative religion because that's how integrated [religion] is in everything that we are working on and deciding and thinking about in life today"John Kerry, U.S Secretary of State(sic), 8/7/13

"Not everything that counts can be counted, and not everything that can be counted counts."

$\sim$ Albert Einstein

Most people do not know that more than one-fourth of the world's population does not eat pork or drink alcohol for religious reasons. Or that one billion do not eat beef. Or that sessions in the United States Congress begin with prayer. Or that sectarian and some other forms of violence witnessed around the world today are linked to religious opinions. These simple basic facts allude to the considerable presence and influence of religion in the world. Yet, as Willoughby Deming observes, most people in the world do not study or reflect on religion in an objective manner (Deming, 2015:2). To most, knowledge of and about religion is not just limited; very little is known about their own religions. This fact that is verified in the Pew Research Center survey $(2010)^{2}$ and in the Stephen Prothero Religious Illiteracy Test, among others (2007) ${ }^{3}$. In these surveys, Americans on the average answered correctly 16 of the 32 questions on religion on the survey. Atheists and agnostics averaged 20.5

1 For a full video visit U.S Department of State, "Remarks at the Launch of the Office of Faith -Based Community Initiatives" www.state.gov/secretary/remarks/2013/08/212781.htm

2 PEW, U.S Religious Knowledge Quiz, Pew Research Center: Religion and Public Life, 2010 http://www. pewforum.org/2010/09/28/u-s-religious-knowledge-survey/

3 Stephen Prothero, 2007. Religious Illiteracy Test, http://www.pewforum.org/files/2007/12/protheroquiz.pdf 
Reclaiming Religion, Religious Studies and the Humanities in the Academy and in National Development

and 20.3 correct answers while Protestant Christians averaged 16 and Catholics averaged 14.7. The fact that Atheists and agnostics along with the Jews and Mormons performed better than the other groups is notable. In this paper, it is argued that religion plays a significant role in human experience; a fact that is clearly noted in existing surveys and also evident in world affairs such as election campaigns, popular culture, to mention just these. Scholars of religion, Prothero,and Gary Kessler, have described religion as a force that influences the lives of everyone for good or for ill (Prothero, 2008: 5; Kessler, 2006:12). In the United States, government officials such as the former secretary of state Madeline Albright, and the former United States secretary of state, John Kerry, have publicly declared the importance of studying religion in understanding general human welfare (Schneider, 2011). On August 7, 2013, during the launch of Faith-Based Community Initiatives, Kerry declared in his speech at that if he were to return to college, he would major in comparative religion because religion is integrated into every facet of life today (August 7, 2013; Schneider, 2011). In a world where people of all faiths are migrating and mingling like never before, we ignore the global impact of religion at our peril," he reiterates (2015; Roewe, 2013). In her book, The Mighty and the Almighty: Reflections on American, God and World Affairs (2006), Albright explains how the failure of Americans to understand other religions "poses one of the great challenges to the nation's public diplomacy" (2006).

This study draws from the understanding of this central role of religion in society, to argue that religion the study of religion as humanities and social sciences is just as significant as the study of the science, technology, engineering and math (STEM) subjects. The paper draws upon the findings of the Teagle/American Academy of Religion (hereafter AAR) survey undertaken in 2015 as well as secondary sources to make a case for reclaiming the central place of religion, religious studies and the humanities in the academic enterprise and in national development in general. ${ }^{4}$ The Teagle/AAR project set out to investigate the long-term impacts of the religious studies major on graduates and to highlight the status of the study of religion in national development. The findings were based on a survey of 1524 graduates from select institutions of higher learning (universities and colleges) in the United States, 200 of which were graduates of East Carolina University. Overarching goals highlighted in the investigation include (1) the career prospects of religious studies majors; (2) a discussion of knowledge and skills acquired by religious studies majors; (3) investigation of the general perception of a degree in religious studies by students who majored in the field and (4) the future prospects of the study of religion in the academy. Knowledge and skills acquired were measured in terms of general areas of competence and students' satisfaction with the program, the pursuit of graduate school, employability, volunteer or participation in the religious organization and in community-based outreach projects including non-profit or other social projects. The main objective was to highlight that knowledge gained in this field of study contributes to knowledge and national development. Findings help to counter general assumptions and misconceptions about religion, religious studies,and the humanities, especially as pertains to relevance and employment of graduates in these areas.

The study employs intersectionality as a framework to argue for interconnectedness and interdependency of religious studies, the humanities,and STEM as separate yet complementary disciplines influence the behavior or reality of the entire social system. Intersectionality acknowledges the complexity and interrelatedness of social reality; a reality spoken to by the humanities. This reality cannot be isolated or compartmentalized as though it does not affect or is not affected by a myriad of factors.

It is a rejection of dichotomous, reductive approaches that don't account for interconnected reality. Reductive approaches are the reason for attempts to delineate, separate and marginalize religion, religious studies, and the humanities. They are the reason why the importance of religion, religious studies, and the humanities are despised. Recognizing this complex relationship, this article argues for intersectionality as a theoretical

4 Mary Nyangweso, "The Long-Term Impacts of the Religious Studies Major on College Graduates, Teagle/ AAR Report, Unpublished, 2015 
Reclaiming Religion, Religious Studies and the Humanities in the Academy and in National Development

framework that affirms the rich interaction of intricate variables as evident in knowledge and in social reality. Intersectionality as an approach recognizes how complex reality informs social conditions and social behavior. As approach, intersectionality is premised on the understanding that people's lives are defined by multiple layered identities which derive from social relations, histories, cultures and other operations of structures of power. As an analytical tool for studying, intersectionality helps one to understand and to respond to the ways in which social issues intersect with other identities and how intersections contribute to the complex reality that informs social behavior. As a tool of analysis, intersectionality helps to reveal how multiple factors and identities inform knowledge and reality are.

\section{RELigious STUdiES}

The study of religion faces many challenges, especially those of recognition, in the academy and in the institutions of higher learning due to overemphasis on the STEM (Tworek, 2013; Mardsen, 1994; Roberts; Lewis; 2006; Kronman; 2007, Wolfe, 1997). As a field that does not rely heavily on empirical evidence, the study of religion is often depicted as a field that does not matter. For instance, in many colleges and universities, there is the general perception that the study of religion is tied to belief and that professors of religious studies are religious and that they proselytize (Kronman, 2007; Lewis, 2006). This misconception does not only distort reality, the impact of such distortion has affected enrollment in religious studies courses. Related to this misconception is the perception that taking a course in religious studies impinges upon one's spirituality and may even make one irreligious. The most believed myth about religious studies is that it offers a major that is impractical in the sense that it does not lead directly to a specialized profession as in the case of other major subjects like those of the Science, Technology, Engineering, and Math (S.T.E.M.) fields (Tworek, 2013).

In most institutions of learning, the study of religion falls under the humanities or the social science designation. It is a discipline of study just like History, English, Biology,and Psychology. Like other core humanities, religious studies strives to overcome misconceptions that consider the study of the humanities a waste of time (Tworek, 2013). Many fail to understand that religion is taught like any subject with the objective of pursuing the knowledge and the understanding of the extraordinary complex phenomenon that religion is. Students are taught how to articulate and reflect critically on various central questions and beliefs and to examine various facets of religious experience from different perspectives. Learning to analyze facts about the origin and role of religion in social behavior is central to the study of religion.

Contrary to assumptions that studying religion makes one less religious, studies indicate that one's beliefs can also be affirmed and strengthened. In fact, scientific findings indicate a correlation between analytical thinking and belief in God (Shenhar, Rand,and Green, 2012: 423-428). Analytical thinking, it is argued, encourages people to think intuitively. According to the Teagle/AAR study findings, most religious studies majors become active participants in their religious institutions and their communities. Questioning and speculating about the nature of divinity or mystical experience is often counterbalanced with the exploration of ritual practices, deep interpretation of scriptural texts. These expose students to deep questions at the center of their religions. Ultimately, they understand their religions wholly. Perceptions that those who study religion must be religious are erroneous. While professors of religious studies, like other professors or administrators, have their own religious inclinations, as academic scholars their responsibility is to present knowledge about religion in a neutral and non-biased way.

Misconceptions about the study of religion are better understood in the historical trajectory of this field. The academic study of religion dates back to the enlightenment period; a period when the questfor compartmentalized knowledge (the German model of Wissenschaft) embraced the spirit of science. In 1910, Friedrich Max Muller declared everyone as being religious and asserted that wherever there was human life, there was a religion (1910). This simple statement became the reason that the study of religion originated. Muller recognized the fact that the sacred is an experience that is found in various religious beliefs and that acknowledgment of 
Reclaiming Religion, Religious Studies and the Humanities in the Academy and in National Development

multiculturalism, and neutrality about beliefs and cultures expanded perceptions of religious world views and hence the study of religion. His view distinguishes between religion and Christianity, between an apologetic theological study of religion and the academic study of religion. Muller is often credited with originating this approach to the study of religious studies. He helped delineate the academic field of study of religious studies at colleges and university from that in the seminaries. While the longstanding and most popular approach to the study of religion is the theological approach which examines religion from the theological approach; the perspective of community believers, Muller introduced the scientific approach to the study of religion that soon revolutionized the study of religion as it introduced questions and assertions that had not been considered in theological discussions (Olson, 2003; Livingston, 2008). As this field of study prospered in the 1950's/60's, with colleges and universities offering courses in eastern and non-Christian religions, it became clear that teaching about religion was different from indoctrination. The change of National Association of Biblical Instructors (N.A.B.I.) to American Academy of Religion (AAR) helped seal this distinction. As Sam Gill explains, religious studies as a field of study became sensitive to multiculturalism and neutrality (Gill, ).

One significant development in this academic approach was that as an intellectual inquiry, the discipline of religious studies was not to endorse a particular creed or religious position. Scholars of religion were to practice what Nathan Schneider calls "selective suspension of judgment about certain truths claims" (2011). As an academic field, the study of religion was designed to introduce students to concepts so they could appreciate the place of religion in the social order. In learning about various forms of religious experiences, students are expected to: 1. Appreciate human values and especially how humans as religious beings create meaning using religion. 2. Appreciate other people's worldviews, cultures, knowledge, and religions in order to appreciate diverse perspectives and to overcome ignorance that is often associated with ethnocentric and prejudiced mindset. 3. Recognize how knowledge about religion informs their history, culture and general knowledge and how interdependent knowledge, cultures and general knowledge is; and 4. Reflect upon their own beliefs as they formulate their own philosophies of life (Livingston, 2008:5-10).

The scientific approach central to academia encouraged employment of various approaches and perspectives and the utilization of various tools of analysis employed in other academic fields such as philosophy, history, anthropology, sociology, psychology, and archeology. James Livingston has described how each approach sheds light on aspects of religious experience that otherwise would be misunderstood. For instance, a theological approach examines religion from the believer's point of view. While this approach employs certain scientific tools of analysis to the study of religion, theology is sometimes criticized for being subjective and apologetic which mean it is geared towards affirming believers' faith beliefs. It should be noted however that theology employs tools of analysis such as literary and textual criticism, hermeneutics and documentary criticism, among others tools of analysis that are also critical. Literary criticism examines events, beliefs, and scripture to explore questions such as "Who authored the Gospels?" "When was it composed?" "What was the author's purpose?" Textual criticism is often used to investigate the authenticity of a scriptural text. Questions explored include whether the text in questions was revised or altered. Using documentary criticism, scholars of religion investigate whether a piece of writing is a whole or separate document and whether it was written by one or numerous authors. As Livingston clearly points out, documentary critics examine scriptural texts, such as the book of Isaiah, to explore whether it was written by more than one author (Livingston, 2008). Hermeneutics as an approach helps in understanding forms of scriptural interpretations.

Historiography, as an approach, is used in the study of religion to investigate historical facts, social -economic factors that influenced the author/ founder of a religion? Anthropology examines religion as a cultural system (Geertz, 1973). Sociology, as an approach, explores religion as a social institution that shapes human experience. Drawing from works of sociologists, such as Emile Durkheim, Max Weber, and Karl Marx among others, sociologists of religion are concerned with the functional role of religion and how in turn religion influences social values such as economic, political, and general social behavior. For instance, Max Weber in his book The 
Reclaiming Religion, Religious Studies and the Humanities in the Academy and in National Development

Protestantism and the Spirit of Capitalism makes serious linkages between religious values, behavior and the rise of modern capitalism (Weber, 1930). Psychology, as a discipline, offers tools that examine religion as it relates to personality development. And finally, philosophy as an analytical tool helps to explore logical claims in religious ideas.

Since as the academic study, religious studies attempt to discover, describe and explain, expressions of the religious life without prejudice. Objectivity is encouraged in order to sustain sensitivity and to maintain the respect of other beliefs. In addition, the field imparts upon students a number of life skills including the ability to think critically, read, write, research, and communicate more effectively. As the findings of the Teagle/AAR demonstrate, the academic study of religion has the objective of explaining the basic facts of a diverse array of religious traditions, including the circumstances of their founding, their history, and their fundamental doctrines and practices, students gain the ability to articulate and dispute, general assumptions about religions. They learn to ask intelligent questions about religious experience that reflect their rigorous thought, analysis, and inquisitiveness often preferred over dogma. Other skills offered by the study of religion include cross-cultural communication, critical thinking skills (analysis, synthesis, research) empathy, tolerance, careful observation, comparative skills, written and verbal prowess, reading and listening, and sensitivity to the construction of meaning. The objective is to ensure that students possess the ability to communicate their understandings of religious issues through speech and writing by formulating clear theses. They should demonstrate the ability to utilize reliable sources and legitimate research to develop coherent arguments that effectively persuade their audience. As they advance, students are expected to be conversant with the history, theories, and methodologies of the discipline. At graduation, they should demonstrate the ability to employ learned insights in reacting to the world in a meaningful way. They should be able to appreciate the diverse nature of the human experience and be able to make mature decisions in a global context. The significance of the study of religion, therefore, lies not just in its centrality to knowledge, but also in its centrality to the realities of human experience. As Stephen Prothero observes, the value of studying religion lies in the fact that it is one of the greatest forces of good and evil in world history. Ignorance about Christian crusades and Muslim martyrdom, for instance, can be literally lethal (2008:5). Ignorance of cultural and religious literacy can be dangerous. Religious illiteracy is dangerous because religion is the most volatile constituent of culture, he argues.

Often, facts about the study of religion are ignored due to misconceptions mentioned earlier. The claim that religious studies major does not lead to employment is not backed up by fact. Contrary to general assumptions that a major in the religious studies does not offer employment prospects, the Teagle/AAR findings indicate that religious studies majors access employment like their peers in other fields of study. Eighty-three percent of those surveyed in the nation and eighty-eight of those surveyed at East Carolina University reported having some form of employment at the time of the survey with fifty-six reporting to have had some kind of employment over the past 18 months (Nyangweso, 2015). Religious studies majors have successfully gone on to professional training in ministry, business (particularly international business), counseling and social work, education, journalism, law, and medicine. Others have moved directly into the job market, taking up positions in government, foreign service, and the Peace Corps, marketing,and management, museums and the arts, nonprofit or non-governmental organizations, publishing, event planning, hospitality, or the service industry. Those surveyed in the Teagle/AAR project indicated that they had been employed in various areas including serving as college professors, administration, anthropology, agriculture and natural resources, business and finance, counselling and mental health, education (K-12), government and public administration, hospitality and tourism, information systems and technology, journalism and public law, library work, manufacturing and construction marketing, medicine and nursing, military, non-profit or community organization, religious organization and transportation ${ }^{5}$ These facts are further supported by the Students' Reviews survey of 25,632

5 Other areas of expertise religious studies majors have worked in can be viewed at http://studyreligion. org/where/index.html. 
Reclaiming Religion, Religious Studies and the Humanities in the Academy and in National Development

alumni which revealed that the unemployment rate of religious studies majors was $2.3 \%$ way below the $6.66 \%$ average of all majors. ${ }^{6}$ A study by Georgetown University Center on Education and the Workforce which examined unemployment rates for 173 colleges supports this argument further. Religious studies was ranked at 14 with $4.1 \%$ of college majors with the lowest unemployment rates.

Further, useful skills and knowledge that religious studies students acquire including, cross-cultural understanding, research methods and critical analysis, are rarely acknowledged. Although these skills are currently sought in any job market due to the diversifying and globalizing job markets, few associate them with religious studies. As existing evidence demonstrates, graduates of religious studies like those in other humanities acquire skills that are highly valued by employers and that these skills are applicable to a wide variety of professional jobs. In a study conducted at a major employing company in the United States, AT\&T, employees with either a humanities or social sciences background were found to be stronger than engineering majors and similar to business majors in administrative skills. Furthermore, graduates in these areas demonstrated the strongest interpersonal skills (Goldston, 2014). As is highlighted in the Teagle/AAR findings, students in religious studies develop skills that enable them to reflect critically on their own selves, their beliefs and how to work effectively with individuals who are culturally different from them. The study helps students to cultivate a sense of social and ethical responsibility that draws from historical experiences of the religious traditions they study. The most unrecognized skill developed by students of religious studies is the ability to writing and speak clearly and effectively.

One significant skill associated with religious studies is that of service. This is a skill that is currently valued in the world because it prepares students to engage their communities in a more informed manner. Eighty percent of those surveyed reported having participated in community service. Through fieldwork and internship opportunities offered by religious studies, they are connected with potential employers. Therefore, the assumption that studying religion or the humanities is a waste of time fail to recognize that religious studies and the humanities offer students skills that are highly valued by employers. Assumptions such as these are responsible for misleading attitudes and misunderstandings about religious studies as a field of study.

The Teagle/AAR project findings indicate that most religious studies graduates reported that their education made a positive contribution to their life. While these graduates appreciate knowledge and skills they acquired in studying religion, most people are unaware of how significant liberal arts skills are to general knowledge. Liberal arts skills which include research competency, communication (reading and writing); ability to interpret data/ information in a critical manner, participation in community service or charitable projects, knowledge in ethical standards, ability to work with diverse populations, and the ability to analyze problems from different perspectives. Further, according to the Teagle/AAR findings, religious studies graduates have similar prospects and achievements in life as other graduates in the humanities and the social science programs. It should not surprise anyone that most surveyed graduates indicated satisfaction with the Program and that the program made a positive contribution to the quality of their life. In the job market, skills count more than one's major. According to Nace Job Outlook, ${ }^{7}$ the top 10 qualities / skills sought by employers include the ability to work in a team, to solve problems, to plan, organize and prioritize, communication skills, ability to obtain and process, analytical skills, technical knowledge, technical knowledge related to jobs, computer skills, and communication skills. A degree in religious studies is therefore as important as any other degree in the humanities and social sciences for preparing a student for varied forms of employment as illustrated in the various professions listed above. While there is no clear correlation between double majoring and employment, the findings further

6 www.studentsreview.com/unemployment_by_major.php3.

7 National Association of College and Employers (NACE) 2013. “Job Outlook: The Candidate Skills / Qualities Employers Want" accessed at www.naceweb.org on September 11, 2014. 
Reclaiming Religion, Religious Studies and the Humanities in the Academy and in National Development

indicate that graduates who were employed reported having pursued a double major to help expand their employability. The study found that over fifty percent of graduates in the nation reportedto have a double major. It can be argued that it is advantageous for students to pursue a double major to increase employment prospects. An investigation of the graduates' interest in pursuing a graduate degree revealed that religious studies majors were also likely to pursue graduate school.

The myth about inaccessibility to employment and that a degree in S.T.E.M is a student's only preparation for medical school ignores the fact that (S.T.E.M) courses are not the only condition for acceptance in medical school as often believed. Skills in the humanities are necessary for a successful degree in the medical career. Recently, the Association of American Medical Colleges has pointed out that one's major is irrelevant when it comes to being admitted into medical school. According to existing data, only fifty-one percent of students enrolled in medical school in 2012 majored in biological sciences. As Goldstone validly observes, "the remaining medical school matriculants majored in the humanities, math or statistics, physical sciences social sciences of specialized health sciences" (Goldstone, 2014). Since employers are often more concerned about the skills than the specific major, as Goldstone observes, companies are willing to train newly graduate in any major for specific jobs (2014). While some companies or organizations might seek specific skills, experience and abilities, many people end up working in careers that are not directly related to their majors. Knowledge that most majors teach transferrable skills is the reason for students to pursue their area of interest as they prepare for career paths. As per the findings, the non-recognition of skills acquired in the field of religious studies and the fact that graduates fail to acknowledge, embrace and to discuss acquired skills at employment reinforce misconceptions that this field of study, religious studies does not offer any skills. Identifying skills students learn and pitching these to potential employers is one way to increase relevance and employability in this profession.

Contrary to general assumptions that the study of religious studies is likely to decrease one's spirituality, the Teagle/AAR findings revealed fascinating outcomes that a degree in religious studies increases personal spiritual growth. Deep knowledge about one's own religion helps one to reflect deeply on one's own spiritual questions. In addition to increasing one's spirituality, a degree in religious studies increases one's open-mindedness. This fact was evident in graduates' openness to participating in nontraditional religions. When students participate in fieldwork which includes visits of religious sites not of their own such as Hindu temples, Mosques, Sweat lodges, Jewish Synagogues as is often with ECU students, they learn about the life experiences of those who are different from them and are likely to appreciate their common values and aspirations.

The findings also showed a link between studying religion and traveling. Most graduates of religious studies are not only involved in studying abroad, they tend to appreciate travel in their efforts to visit religious sites and they also tend to engage in social issues. As the study that informs, religious studies transforms perspectives and actually empowers students to be good citizens. As the findings of the Teagle/AAR study illustrate, religious studies is not only important to understanding the past and the society humans live in, it is crucial to cultivating good citizenry. As Prothero reminds us, a good citizen should be exposed to a curriculum that promotes cultural diversity and harmonious living. The study of religion, as an academic field, emerges from the realization of this pivotal role of religion in society.

\section{The Humanities}

As indicated earlier, the critique of religious studies is also extended to the humanities as a whole. Like religious studies, the humanities have been described as being in crisis. It is argued that the humanities have no purpose because they lack cultural and economic relevance and that the humanities as an academic field produce work that is inaccessible to the public. Critics of the humanities have gone as far as dissuading students not to take courses in the humanities because of perceived assumptions that they are not immediately employable as those in the STEM field. These critics have referenced times of economic recession, to argue that resources 
Reclaiming Religion, Religious Studies and the Humanities in the Academy and in National Development

should not be spent on studying the human condition, (Heidi, 2013; Terras, Priego, Liu, Rockwell, Sinclair, Hensler and Thomas, 2013). ${ }^{8}$ These critiques of the humanities often disregard the facts that indicate that on average, humanities graduates have a comparable employment rate to graduates within other degrees. A study conducted in 2012 indicates that two-thirds of the humanities and social sciences graduates enter the private sector, primarily the financial and business sectors followed by wholesaling and retailing (Terras et al, 2013). These sectors represent some of the fastest growing areas within the economy. The survey of $652 \mathrm{U}$. S. born chief executive officers and heads of product Engineering conducted in the study showed that almost $60 \%$ had a degree in the humanities (Terras et al, 2013).

The humanities are academic disciplines whose purpose is to understand and interpret the human experience from individuals to entire cultures, engaging in the discovery, preservation, and communication of the past and present record to enable a deeper understanding of contemporary society. They attempt at answering questions such as the following. What is a human being? What is the origin and meaning of life? How do humans advance and manage change if they have no notion of the past? How can humans understand themselves if they have no notions of a society, culture or a world that is different from the one they live in? These and other existential questions have concerned humans everywhere in the history of human beings. By asking basic questions of life is central to the humanities, the humanities cultivate rational reflection; a fundamental skill in developing and directing answers that helps one to resolve problems in life. Learning to ask relevant questions and distinguishing them from irrelevant ones is an intellectual activity that is necessary for personal growth and even success at work.

In order for students to gain abilities in integrative thinking, imagination, creativity, discovery, and to be trained in good citizenship, they must learn about their societies' culture and values that define these cultures as taught in the humanities. It is in regard to such questions that the American Academy of Arts and Sciences (hereafter, AAAS) announced a hidden crisis in the humanities and social sciences (King, 2015). The Academy's report concludes, that, now more than ever the spirit of international cooperation, the promotion of trade and foreign investment, the requirements of international diplomacy, and even the enhancement of national security depend in some measure on an American citizenry that is trained in the humanistic and the social science disciplines. These include the languages, transnational studies, moral and political philosophy, the global ethics, and international relations (AAAS, 2013: 57). Other benefits of studying the humanities include revealing how people have tried to make moral spiritual; and intellectual sense of the world. Through the humanities, students learn empathy, and how to deal critically and logically with subjective complex imperfect union situation.

In the report, the academy specifically argues that only citizens who are educated in the broadest possible sense will lead America into a bright future. In order to participate in their own governance and engage the world, these citizens should be experts in national security, and be equipped with cultural understanding. They should be knowledgeable about how social dynamics and language proficiency inform foreign services, military success and ultimately complex global conflict. Such citizens should be able to appreciate how differences and commonalities have shaped the world history. In chapter four, the report describes how significant intercultural knowledge is. The three overarching goals of education identified in the report are; 1) Educating Americans in the knowledge, skills, and understandings they will need to thrive in a twenty-first-century democracy. 2) Fostering a society that is innovative, competitive and strong and, 3). Equipping the nation for leadership in an interconnected world. As Thomas Jefferson's observes, the goals and objectives of education are:

to give every citizen the information he needs for transaction of his own business; to enable him to calculate for himself, and to express and preserve his ideas, his contracts and accounts in writing; to improve by reading his morals and faculties; to understand his duties to his neighbors and country, and to discharge with competence

8 Terras, M. Priego, E. Liu, A., Rockwell, G., Sinclairs, S. Hensler, G., and Thomas L. 2013. "The Humanities Matter" Infographic, 4humanities.org/ infographic

American Research Journal of Humanities and Social Sciences Page 8 
Reclaiming Religion, Religious Studies and the Humanities in the Academy and in National Development

the following confided to him by either; to know his rights ... and in general, to observe with intelligence and faithfulness all the social relations under which he shall be placed - Thomas Jefferson from "Report of the commissioners for the University of Virginia" August 4, 1818.

They encompass literature, classics, ancient and more languages, history, philosophy, medial studies and the five performing arts and other related subjects. Intellectual activities are grouped into categories, namely; the natural sciences, the social sciences and the humanities. The 1945 Harvard report and the panel of the American Association and Universities (AAC\&U) Greater Expectations from 2002 describe the aims of the study of natural sciences as the understanding of our physical environment in order to have a suitable relation to it. The social science is intended to produce an understanding of the social environment and of human institutions, in general, to help students achieve a proper relationship with society. The humanities, on the other hand, are concerned with studying language, literature, history, jurisprudence, philosophy, archaeology, religion, ethics, including those aspects of social sciences which have humanistic content and employ humanistic methods. The humanities help students to explore what it means to be human and to understand how humans create meaning in their relations with one another (Buck et al, 1945: 58f).

Of the three groups, often the sciences, are given a higher value because they easily translate into technology. The excitement of scientific discovery is rooted in its potential to save lives and enhance research. The focus on scientific discovery, as a model of assessing knowledge, has increasingly led universities to direct their efforts and financial support to the natural and physical sciences with less focus and concern placed on the humanities. This focus is embedded in the western epistemological values that prioritize the reductionist model of categorizing things. This model has been successful in the sciences and engineering because of what Verschueren calls "quantification and its quest for precision" (Verschueren, 2001: 399). The general assumption about the reduction model is that the sciences give us facts and facts cannot be wrong. Although this approach is popular in the sciences and associated disciplines due to its problem-solving technique, in reality, social problems are more complex. The assumption that "figures can't be wrong" attach a lot of trust to data, facts,and figures. While this model is central to knowledge, the construction of the imaginative models of experience belongs to the humanities. Neither model should be considered inferior to the other.

Critics of the humanities have argued that the decline in the humanities is an indicator of its irrelevance. While it can be argued that the humanities have declined, in terms of enrollment since the 1970's, the decline has stabilized over time. It is often noted that while the enrollment in the 1970's was at 17.2 percent, between 1980 's to 2011 enrollment dropped to about seven percent. What is often not acknowledged as a factor regarding this decline, is the fact that women's interest in STEM fields also increased as gender gap issues got addressed over time. ${ }^{9}$ As women have steadily selected social sciences, about 40 percent of women are currently majoring in social sciences. While women' interest in the social sciences should be applauded, it is erroneous to claim that the decline in the humanities is due to irrelevance and non-employability of graduates. Rather, the diversifying trend in academic should be acknowledged as a positive thing and a shift that should also concern anyone who recognizes the relevance of Religious Studies and the humanities to knowledge and general national development.

Speaking on the importance of the humanities in national development, David Souter, former U.S Supreme Court justice (1990-2009) observes that studying the humanities is vital not only to scholars but to the prosperity of the nation. What the humanities have to teach us, he argues, is the variety of truth; the provisional nature of conclusions; the sources of illumination from people of other perspectives and the magic that can occur when they are combined (Daniels, 2014). According to him, people who study the humanities are people who avoid

9 Tworek, Heidi. 2013. "The Real Reason the Humanities Are in Crisis: Women Started Deserting Subjects like History and English Decades Ago" The Atlantic, https://www.theatlantic.com/education/archive/2013/12/ the-real-reason-the-humanities-are-in-crisis/282441/ 
Reclaiming Religion, Religious Studies and the Humanities in the Academy and in National Development

indoctrination in the sense that they prefer to arrive at rational ideas. The humanities, he argues, helps to promote the kind of tolerance, that degree of healthy self-doubt. Learned Hand refers to this kind of tolerance and self-doubt as healthy because it is the realization that one may be mistaken. The humanities promote the spirit of liberty that Oliver Cromwell is quoted as a reference in his statement to the scots (AAAS, 2013: 61; Learned Hand, 1944).

The humanities instill in students how complex and interconnected knowledge and reality is. Speaking at the American Academy of Arts and Sciences in the Cambridge forum sponsored by the President's Committee on the Arts and the Humanities, Neil L. Rudenstine has argued, "I believe that we should not draw too firm a line between the humanities and other academic fields of learning because of great humanities' texts ... lead us very quickly outside the realm of the humanities, if we want to understand their full significance (Gewertz, 1998)." As Ramaley validly observes, the $9 / 11$ events impressed upon universities and colleges the need to move towards "producing ethical and compassionate graduates, courageous enough to act on their conviction and reflective in shaping society's larger values" (Ramaley, 2002). Therefore, while disciplinary demarcations are probably necessary for pedagogical reasons, they should always translate into a practical experience to be realistic. The interconnectedness of the humanities with the natural sciences and the social sciences should be explained in terms of a knowledge puzzle process with each piece of the puzzle viewed as significant and a reflection of experiential reality. Simply stated, it is impossible to study the arts and humanities without coming to some understanding of the social sciences and natural sciences, and vice versa (Gewertz, 1998).

Humanities are vital in understanding more fully what it means to be human. The need to understand the human condition provides a new way of thinking about who and what humans are, and what the world is all about. It is important to recognize that the humanities are foundational to higher education as a significant step in connecting educational facts to human experience. The humanities' attempt to understand the human condition from the inside, as it were, treating the human person as subject, as well as object, agent, as well as acted-upon (McClay, 2009: 4). Recognizing this fact, Patricia Cohen of the New York Times observes, "humanities offer knowledge with a different purpose; knowledge that is prerequisite to personal growth, is necessary (2009). In fact, Wilfred McClay is right in observing that unlike the natural sciences and social sciences, it is the distinctive task of the humanities to "grasp human things in human terms, without converting or reducing them to something else: not to physical laws, mechanical systems, biological drives, psychological disorders or social structures. This fact is supported by those who consider culture as important. Appreciating this fact will permit all forms of knowledge to shape and nourish the way we live" (McClay, 5).

The humanities other goal is the cultivation of intercultural knowledge. Senator J. William Fulbright is particularly noted for advocating this knowledge. In his book The Price of Empire, he describes the essence of intercultural education as the acquisition of empathy- the ability to see the world as others see it, and to allow for the possibility that others may see something we have failed to see or may see it more accurately (Fulbright, 1989). He explains how empathy is critical to national security, domestic stability and economic competitiveness. In the survey study mentioned earlier, the appreciation of culture as humanity was clear. Of those surveyed 55 percent explained that they appreciated works of fiction, plays and short stories. Fifty percent explained that they buy a novel, poetry and play and 76 percent indicated that their lives are richer for having the opportunity to visit or view the historic environment (Tierra, 2013)

The production of responsible citizens within a pluralistic society is the ultimate goal of the humanities and religious studies in particular. Religious studies and the humanities cultivate skills and insights for addressing cross-cultural communications, critical empathy, tolerance, and critical thinking skills (analysis, synthesis research). Other skills include the ability to make interdisciplinary connections, reflexivity, flexibility, adaptability, careful observation, reading and listening, comparative skills, written and verbal prowess and 
Reclaiming Religion, Religious Studies and the Humanities in the Academy and in National Development

sensitivity to the construction of meaning. Students are prepared for various professional careers. As Kessler observes, "a wide variety of employers are looking for people who are tolerant of diversity, are able to learn from others, are adaptable to new situations and have knowledge of history and international affairs" (Kessler, 2006: 12). During an interview for the students' newspaper Daily Bruin, the dean of the humanities division at the University of California Los Angeles (UCLA) was asked whether the humanities graduates are unemployable. He responded:

We are heirs to a world,' I stated, 'that of World War II and its aftermath, when states like Nazi Germany claimed that there was such a thing as 'a life unworthy of life,' the basis on which Germans claimed the right to terminate the lives of the mentally ill, those with birth defects, and those they simply scorned and hated, like gypsies, Jews, and communists'...if anyone says 'no one ever died of the humanities', he has not thought much about what happens when states claim the right to define what humanity is, or who is good and who is evil, and therefore justify movements like ethnic cleansing. It is important to be reminded of the intrinsic humanity of all peoples, however different ethnically, religiously, politically, or even medically (Spiegel, 2008). ${ }^{10}$

The argument made by Spiegel explains in a nutshell the central goal of the humanities and by implications the core studies within this discipline. This same goal is at the heart of religious studies. This goal is as fundamental to academia and national development as STEM field of study and should be acknowledged.

\section{CONCLUSION AND RECOMMENDATIONS}

Religion, Religious studies, and the humanities are not only central and relevant today, and to higher education, they are fundamental to national development in this changing world. It is important that this significant role is clearly documented and publicized. This claim does not diminish other knowledge areas or disciplinary demarcations that highlight the importance of specialization. It highlights the importance of acknowledging that multiple approaches to knowledge help in the broadening unique perspectives necessary for authentic contribution to general knowledge. As long as human nature and behavior are central to knowledge production; religious studies and the humanities will remain vital. This paper has demonstrated that arguments about the demise of the field of religious studies or of the entire humanities are often misled because they are not based in facts. Instead, they are based in misinformed perceptions that any field of study can or should operate independently. Misconceptions such as these point to an urgent need for a paradigm shift and a redefinition of the purpose of knowledge in society. There is an urgent need to recognize that humans are not only reliant and dependent upon each other, but that their success in this world is dependent upon the interconnectedness of skills and values. Values and skills are not independent of reality. As scholars such as McClay have argued, there is need to recognize and appreciate the cultural capital of the humanities (2009).

To recognize that religious studies and the humanities are fundamental pieces of the knowledge and skills puzzle is to recognize that the goals of knowledge acquisition are broad and that even the study of religious studies and the humanities are that important. It is important that scholars of religion and the humanities articulate this fact to students in all fields of study in order to recognize and embrace diverse forms of knowledge and the necessary skills these forms of knowledge offer for success in the globalizing world. The fact that skills such as the ability to think critically and to communicate effectively are gained in the study of religion as in other humanities, and that these skills are sought by most employers, as indicated earlier, needs to be made clear to all students. Students need to learn that effective interaction with individuals from other cultural backgrounds is not only central to socialization, it is also key to social networking and success in employment and society in general.

10 Gabrielle M. Spiegel, 2008. "The Case for History and the Humanities," American Historical Association, https://www.historians.org/publications-and-directories/perspectives-on-history/january-2008/thecase-for-history-and-the-humanities 
Reclaiming Religion, Religious Studies and the Humanities in the Academy and in National Development

As per the findings of the Teagle/AAR study, employment is an area of concern for those studying religious studies and the humanities. One key finding of this study is that graduates of religious studies perform well in employment after graduation and that most of these graduates are as equipped and prepared for employment and for responsible citizenry like other graduates in the nation. The other finding is that, religious organizations are significant employers in the world. This fact, is,however, not made clear to the students before graduation. The knowledge that religious studies majors are prepared for employment like students in other fields of study is revealing given general assumptions discussed above. According to the study, religious studies majors are better equipped with life skills specifically those needed for effective interaction with people of different cultures. This fact ought to be emphasized to students.

Drawing from the findings in this study, it can be argued that the future prospects of religion, religious study and the humanities is not only sound and relevant, it must be appreciated.While there is need to increase creativity for adaptability to contemporary needs, given the evolution of all disciplines, and general realities on the ground, religious studies should reinvent and redesign its curriculum to develop relevant courses and optional tracks that broaden while emphasizing specific knowledge areas. The discipline should highlight the interdisciplinary nature of this field of study in order to appeal to the needs of prospective students. The current shift that is occurring in most religious studies departments and programs is focused on diversifying the course menu from offering only conservative biblical studies courses to offering courses that examine the role of religion in societal spheres such as social issues, security studies, peacebuilding, and science. This initiative is intended to demonstrate the relevance of religion, religious studies and the humanities to social development. When areas of specialization are clearly structured to speak to social reality, students will appreciate the relationship between religious studies, and other disciplines. If religious studies and the humanities continue this creative endeavor their relevance in national development will endure.

Relevance can also be promoted through engaged scholarship. By engaging local, regional and the community at large, religious studies and the humanities will cultivate collaboration and networking initiatives necessary in revitalizing life skills that the community desires. Further, when students are exposed to different values, cultures and general experiences through participant observation programs such as the study abroad programs, they are enabled to access opportunities that help to broaden their perspectives. This skill is direly needed in the globalizing world. Relevance, as a general area of concern, can also be addressed by initiating new interdisciplinary courses such as "religion and science," "religion and sexuality," "religion and public health" to mention but a few. Interdisciplinary initiatives demonstrate interdependence and interrelatedness of knowledge. While it is important to emphasize the difference as a way of appreciating unique and special contributions of each specific fields of study, when the difference is made into absolute independent, it contradicts reality. When the interconnectedness of various field of knowledge is acknowledged reality is acknowledged as well.

\section{REFERENCES}

1. AAAS, 2013. The Heart of the Matter: The Humanities and Social Sciences for a Vibrant, Competitive and Secure Nation, Cambridge Massachusetts.

2. Albright, Madeline. 2006. The Might and the Almighty: Reflections on America, God, and World Affairs. Harper Perennial

3. American Academy of Arts and Sciences. 2013. "Heart of the matter: The Humanities and Social Sciences for a Vibrant, Competitive and Secure Nation,” www.humanitiescommission.org/_pdf/hss_report.pdf.

4. American Academy of Religion. 2004. "Why Study Religion?" accessed at http://studyreligion.org/site/ about.html

5. Annadale, 1998. The Sociology of Health and Medicine: A Critical Introduction, Polity Press. 
Reclaiming Religion, Religious Studies and the Humanities in the Academy and in National Development

6. Blooms, Allan. 1987. The Closing of the American Mind: How Education Has Failed Democracy and Impoverished the Souls of Today's Students, Simon and Schuster.

7. Buck, PH. Finley, J.H., Demos R. Hoadley, L. Hollinshed, B.S, Jordan W. K, et al. 1945. General Education in a Free Society: Report of the Harvard Committee, Cambridge, Massachusetts: Harvard College.

8. Cohen, Patricia. 2009. "In Tough Times, the Humanities Must Justify their Worth," New York Times, February 24 accessed at http://www.nytimes.com/2009/02/25/books/25human.html on July 2014.

9. Daniels. Melissa. 2014. "Former Supreme Court Justice Makes Case for Humanities in Speech at CMU" Triblive, accessed at tribulive.com/news/Allegheny/69379 on December 24, 2016.

10. Deming, Willoughby. 2015. Understanding the Religions of the World: An Introduction, Wiley-Blackwell.

11. Dirda, Michael. 2015. "The Future of the Humanities: Readings" Humanities: The Magazine of the National Endowment for the Humanities, 36(6) www.neh.gov/humanities/2015/november/feature/the_future_the_ humanities_reading

12. Engel George L. 1977. "The Need for a New Medical Model: A Challenge for Biomedicine" Science, 196: 129-136.

13. Fulbright, J. William. 1989. The Price of Empire, Pantheon. See also http://eca.state.gov/fulbright/aboutFulbright/history/j-William-Fulbright/j-William-Fulbright-quotes.

14. Geertz, Clifford. 1973. Interpretation of Cultures, Basic Books.

15. Gewertz, K. 1998. "Rudenstein Emphasizes Importance of Arts, Humanities in Education," Harvard University Gazette accessed at www.hno.harvard.edu/gazette,1998/0319/RudenstineEmpha.html.

16. Goldstone, Lizbeth. 2014. "Uncovering the Myths about Majors Careers," PPT University of California Counselors Conference, accessed at slideplayer.com/slide3895391/

17. Harpham, Geoffrey. 2008. "National Humanities Center," Wake County Physician, October.

18. Jefferson, Thomas.1818. "Reportof theCommissioners for the University ofVirginia" Vindicating the Founders: Race, Sex, Class and Justice in the Origins of American by Thomas G. West, www.vindicatingthefounders. com/library/jefferson-to-uva-commisioners.html

19. Kessler, Gary E. 2006. Studying Religion: An Introduction Through Cases, NY: McGraw-Hill Education.

20. Kerry, John. 2013. "Remarks at the Launch of the Office of Faith-Based Community Initiatives" U.S Department of State: Diplomacy in Action, August 7, www.state.gov/secretary/remarks/2013/08/212781.htm

21. 2 2015. "Religion and Diplomacy: Toward a Better Understanding of Religion and Global Affairs," America: The National Catholic Review http://americamagazine.org/issue/religion-and-Diplomacy

22. 2015. We Ignore the Global Impact of Religion at Our Peril” America Jesuit Review, http:www. americamagazine.org/religionand diplomacy

23. King, Charles, 2015. "The Decline of International Studies: Why Flying blind is Dangerous" Foreign Affairs July/August, accessed at www.foreignaffairs.com on July 25, 2015.

24. Kronman, Anthony T. 2007. Education's End Why Our Colleges and Universities Have Given Up on the Meaning of Life, Yale University Press.

25. Learned Hand, 1944. "The Spirit of Liberty," http://www.btboces.org/Downloads/1_The\%20Spirit\%20 of $\% 20$ Liberty $\% 20$ by $\% 20$ Learned $\% 20$ Hand.pdf

26. Lewis, Harry R. 2006. Excellence Without A Soul: Does Liberal Education Have a Future? Public Affairs. 
Reclaiming Religion, Religious Studies and the Humanities in the Academy and in National Development

27. Livingston, James C. 2008. Anatomy of the Sacred: An Introduction to Religion, Sixth Edition. Upper Saddle River: Prentice Hall.

28. Marsden, George. 1994. The Soul of American University: From Protestant Establishment to Established Nonbelief, Oxford University Press.

29. McClay, Wilfred M. 2009. "The Burden and Beauty of the Humanities," American Educator, Winter 20092009 accessed at www.aft.org/sites/default/files/periodicals/mcclay.pdf

30. National Association of College and Employers (NACE) 2013. "Job Outlook: The Candidate Skills / Qualities Employers Want" accessed at www.naceweb.org.

31. Mary Nyangweso, 2015. "The Long-Term Impacts of the Religious Studies Major on College Graduates, Teagle/AAR Report, Unpublished.

32. Muller, Friedrich Max. 1910. (2010). Selections from Buddha, Kessinger Publishing LLC...

33. Oakley, Francis. 2002. "Data Deprivation and Humanities Indicators in making the Humanities Count: The Importance of Data," American Academy of Sciences, edited by Robert M.

34. Olson, Carl. 2003.Theory and Method in the Study of Religion: Theoretical and Critical, Wadsworth/ Thompson, Belmont CA

35. O’Shaughnessy, Lynn. 2011. "25 College Majors with the Lowest Unemployment Rates" Money watch, November 16, accessed at www.cbsnews.com/news/25college_majors_withlowestunemploymentrates

36. Solow, Francis Oakley, Phyllis Franklin, John D’ Arms and Calvin C. Jones Cambridge MA,

37. Pals, Daniel. 2006. Eight Theories of Religion, Oxford: Oxford University Press.

38. PEW, U.S Religious Knowledge Quiz, Pew Research Center: Religion and Public Life, 2010 http://www. pewforum.org/2010/09/28/u-s-religious-knowledge-survey/

39. Pilgrim, David. 2002. The Biopsychosocial Model in Anglo-American Psychiatry, Past, Present and Future," Journal of Mental Health 11:585-594.

40. Prothero, Stephen. 2008. Religious Literacy: What Every American Needs to Know ... and Doesn't. Harper One.

41. 2007.ReligiousilliteracyTest,http://www.pewforum.org/files/2007/12/protheroquiz.pdf

42. Ramaley, J. 2002. "Greater Expectation: A New Vision for Learning as a Nation Goes to College." National Panel Report, Washington DC, Association of American Colleges And Universities.

43. Roberts, John H. and James Turner. 2000. The Sacred and the Secular University. Princeton University Press.

44. Scheer, J. and Groce, N. 1988. Impairment as a human constant: cross cultural and historical perspectives on Variation," Journal of Social Issues, 44(1): 22-37.

45. Schneider, Nathan. 2011. "Why the World Needs Religious Studies," Religion Dispatches accessed at religiondispatches.org, July 24, 2015

46. Shenha, Amita. 2012. David Rand and Joshua Green, Divine Intuition: Cognitive Styles Influences Belief in God" Journal of Experimental Psychology, General Vol 141(3), 423-428.

47. Shuttleworth, R. and Kasnitz, D. 2004. Stigma, community, ethnography: Joan Ablon's contribution to the anthropology of impairment/disability..Medical Anthropology, 18(2): 139-159.

48. Smuts, Jan Christiaan. 1926. Holism and Evolution, London: Macmillan. 
Reclaiming Religion, Religious Studies and the Humanities in the Academy and in National Development

49. Spiegel, G. M. 2008. "The Case for History and the Humanities," American Historical Association: Perspectives on History: The Newsmagazine of the American Historical Association accessed at http://www.historians. org/perspectives/issues/2008/0801/0801/080/pre1.cfm

50. Tavakoli, Hamid R. 2009. "A Closer Evaluation of Current Methods in Psychiatric Assessments: A Challenge for the Biopsychosocial Model" Psychiatry, (Edgemont), 6(2): 25-30

51. Terras, M. Priego, E. Liu, A., Rockwell, G., Sinclairs, S. Hensler, G., and Thomas L. 2013. The Humanities Matter" Infographic, 4humanities.org/ infographic

52. Tworek, Heidi. 2013. The Real Reason the Humanities Are in Crisis: Women Started Deserting Subjects like History and English Decades Ago" The Atlantic, https://www.theatlantic.com/education/archive/2013/12/ the-real-reason-the-humanities-are-in-crisis/282441/

53. U.S. Department of State. 2013. Remarks at the Launch of the Office of Faith-Based Community Initiatives" www.state.gov/secretary/remarks2013/08/212781.htm

54. Verschuren, P. 2001. "Holism versus Reductionism in Modern Social Science Research: Quality and Quantity." Vol. 35. 389 - 405.

55. Weber, Max. 1930. The Protestant Ethic and the Spirit of Capitalism, Unwin Hyman: London \&Boston.

56. WHO, 2011. World Report on Disability, 4-5.

57. Wolfe, Alan. 1997. A Welcome Revival of Religion in the Academy" The Chronicle of Higher Education September 19, 1997.

Citation: Mary Nyangweso. "Reclaiming Religion, Religious Studies and the Humanities in the Academy and in National Development" American Research Journal of Humanities and Social Sciences, vol 5, no. 1, 2019, pp. 1-15.

Copyright (C) 2019 Mary Nyangweso, This is an open access article distributed under the Creative Commons Attribution License, which permits unrestricted use, distribution, and reproduction in any medium, provided the original work is properly cited. 